\title{
Apuntes para una ética y jurídica de la información y la documentación: la centralidad de los principios de autonomía, reciprocidad y solidaridad
}

\author{
Some notes on Information Ethics and Law: the centrality of autonomy, reciprocity and solidarity
}

\section{Francisco Javier GARCíA MARCo}

Universidad de Zaragoza, jgarcia@unizar

\begin{abstract}
Resumen
Se introduce el volumen monográfico de Ibersid 2010, dedicado a los aspectos éticos y legales de los sistemas de información y documentación, con una reflexión sobre algunos principios centrales para una ética y una jurídica de la información. Tras introducir el lugar central de la información y la documentación en los procesos de comunicación y memoria social, se presentan cuatro ejes básicos para organizar sus problemas éticos y legales: libertad y coacción, verdad y engaño, transparencia y seguridad, y aportación y recompensa. Se defienden los valores de autonomía, reciprocidad y solidaridad, frente a los de coacción y explotación, aunque se reconoce que todos ellos forman parte de la realidad de la vida social tal y como ha resultado de la evolución biológica y cultural. Es el profesional y el científico el que, en cada situación, debe posicionarse respecto a los cuatro ejes, aunque sin perder de vista los valores con los que, en último término, se alinea.
\end{abstract}

Palabras clave: Información y documentación. Ciencia de la Información. Ética. Filosofía del derecho. Autonomía. Reciprocidad. Solidaridad. Coacción. Explotación.

\section{Introducción}

Es una satisfacción tener la oportunidad de presentar el cuarto número de la revista Ibersid, resultado a su vez de trabajos evaluados por pares presentados en la decimoquinta edición de su congreso homónimo.

Este año lbersid está centrado en los aspectos legales y éticos de los sistemas de información y documentación. Se trata a la vez de un tema que hace tiempo que estaba en la agenda de la Red Ibersid, y que ciertamente estábamos esperando abordar. Han colaborado especialistas de ocho países de América y Europa con las más diversas creencias y posicionamientos políticos, ofreciendo perspectivas muy diversas sobre temas que van desde la propiedad intelectual y

\begin{abstract}
The 2010 Ibersid volume, devoted to the ethical and legal aspects of information and documentation systems, is introduced with a reflection on some pivotal principles of information and documentation ethics. After an exploration of the central role that information and documentation has inside the social processes of communication and memory, four axis are presented that might be useful to organize the ethical and legal discussions on this area: freedom and coercion, truth and deception, transparency and security, and contribution and reward. The values of autonomy, reciprocity and solidarity are defended against coercion and exploitation. But it is understood that all of them are part of social life, as it has evolved throughout the natural and cultural history. It is the information professional and scientist who, in each situation, must explore his position with reference to these axes, but without forgetting the values he truly believes in.
\end{abstract}

Keywords: Information Science. Library Science. Ethics. Legal philosophy. Autonomy. Reciprocity. Solidarity. Coercion. Exploitation.

la educación informacional al derecho de la información y la transparencia informacional, entre muchos otros.

\section{Una cuestión central para la ciencia de la información}

Abordar los aspectos éticos y legales de la información y la documentación es una cuestión absolutamente necesaria.

En la medida en que la ciencia de la información es una ciencia social -concretamente una ciencia de la información social registrada- y conlleva el ejercicio de un conjunto de actividades profesionales desarrolladas en sociedad que incluyen, claro está, la enseñanza y la investigación-, los aspectos éticos y legales son 
ineludibles, y, en definitiva, el referente último de sus esfuerzos, quedando incluso por encima del desarrollo tecnológico y metodológico, que, con ser muy necesarios, son, al fin y al cabo, tan solo medios en función de fines que se establecen en el marco de la discusión ética y a los que se da forma mediante el ejercicio del derecho.

Aunque sería perfectamente posible tratar las cuestiones éticas y legales de forma separada, y de hecho ese es un enfoque común en la literatura científica, hemos elegido abordarlas conjuntamente, porque Ibersid se caracteriza por buscar perspectivas amplias e interdisciplinares. La conexión entre ambas es, por otra parte, obvia. La ética trata de la forma de comportarse en sociedad y el derecho estudia - se esfuerza entorno a- la forma de expresar la ética aceptada en el marco de la estructuración social del poder, con sus formulaciones, conflictos y consecuencias. En definitiva, ambas disciplinas se ocupan de la regulación del comportamiento humano en la sociedad.

Con todo, las diferencias también son notables y se deben reseñar. El derecho es coactivo, amparado en el monopolio en el uso de la fuerza que ejerce el estado; y se articula y ejerce desde los poderes del estado-o, en el caso de organizaciones sociales sin estado, de la tribu, o la familia. La ética, sin embargo, se adopta de forma voluntaria, aunque está sujeta muchas veces a coacción social o grupal: Cuando un grupo comparte una ética, puede ejercer una presión sobre los miembros del grupo mediante el apartamiento y la exclusión. Así que, en cierta manera, existe un continuo entre ética y derecho, y la coacción es un elemento importante cuando se pasa del plano individual al grupal, o se desciende del grupal al individual.

\section{Un lugar propio en el teatro ético y legal contemporáneo}

A los profesionales y académicos de la información, las cuestiones éticas y legales nos afectan de una manera propia, aunque ciertamente los principios, métodos y conflictos básicos son comunes a los que se plantean en otras ciencias y actividades humanas. Incluso, muchos aspectos éticos y legales que se nos plantean son idénticos lógicamente a los que se presentan en los ámbitos de la gestión o de la investigación científica, por poner algunos ejemplos.

Lo que sí es absolutamente idiosincrásico del problema ético y legal de la información y la documentación es que se circunscribe a un dominio específico de la vida social, que le da unidad.
Por un lado, la información y la documentación se sitúan dentro del mundo más amplio de la comunicación social, junto con las ciencias de la comunicación y de la educación, sin duda más visibles para el ciudadano medio y la gran mayoría de los profesionales y académicos. En la medida en que nuestras disciplinas se encuadran en el ámbito de la comunicación social, son, por tanto, una parte del medio en el que se visualizan, realizan y posibilitan las interacciones sociales. Ocupan, por tanto, un lugar central y propio dentro de la vida social.

Pero, de forma más exclusiva, la ciencia de la información se inserta en un punto clave del procesamiento social de la información: la conservación y recuperación de la memoria social, o, si se quiere expresar de forma más concreta, de la preservación y puesta en valor de aquellos mensajes que, con diferentes plazos de caducidad, merecen ser reutilizados y transferidos dentro del ciclo de transferencia del conocimiento que se produce entre las generaciones $y$ entre las personas que continuamente migran su posición dentro del sistema sociales.

En virtud de su doble centralidad, las unidades y servicios de información constituyen, pues, un lugar perfecto para potenciar o cortocircuitar los procesos de comunicación y memoria social, y, en definitiva, los procesos de transferencia cultural entre las generaciones y las personas. El campo de trabajo de la información y la documentación no es, pues, solo un campo de actividad humana, sino un área de conflicto permanente, un territorio de lucha. No es extraño, pues, que conceptos como el de neutralidad ocupen un lugar central en la ética de bibliotecarios, archiveros, documentalistas y gestores de contenidos, aunque luego dicha neutralidad sea continuamente puesta en entredicho desde dentro y desde fuera.

En cualquier caso, como numerosos teóricos de nuestra disciplina han resaltado, el control y la manipulación del flujo de la información y la memoria social son tanto instrumentos como evidencias del poder social; y, por ello, la información y la documentación se sitúan en el centro de los problemas éticos contemporáneos.

No hay que olvidar, finalmente, que la explosión de la World Wide Web ha propulsado las opciones y dilemas éticos entorno a la información y la memoria social a una dimensión global, que acompaña, codo con codo, a la construcción de una economía mundial y de un poder global. Se trata del surgimiento de una nueva estructura cultural, social y económica, que entra en conflicto con las estructuras existentes, de ámbito regional, nacional o local; $y$, en definitiva, de una 
mutación de nivel histórico, plagada de reajustes y fracturas. El debate ético y legal sobre la información, pues, se encuentra en la vanguardia de la globalización, y se tiñe ineludiblemente de las graves necesidades de integración y dilucidación de perspectivas muy diferentes nacionales, ideológicas, religiosas, etc.- que la acompañan.

\section{Un tema conflictivo}

Paralelamente, las cuestiones éticas y legales de la información y la documentación no son solo un tópico inevitable; son también un tema conflictivo. En el fondo, esto es así porque constituyen un trasunto de la diversidad de perspectivas que coexisten sobre la organización de la vida social y económica, de la que la información y la documentación son sólo una parte, por mucha centralidad que quiera dársele.

Desde esta perspectiva agónica de la ética y del derecho que planteamos en estas páginas —en las que se busca en primer lugar la constatación de la realidad, una realidad que es inherentemente conflictiva-, los problemas éticos se pueden plantear como pares de opuestos, que luego se estructuran de alguna manera en sistemas éticos.

Entre todos los posibles, hemos destacado varios ejes éticos de especial relevancia que pueden ayudar a organizar, si quiera someramente, el enorme universo de problemas éticos que se plantean en las profesiones de la información y la documentación.

Desde nuestro punto de vista, los ejes de conflictos que tienen un carácter central para entender los debates éticos y jurídicos de nuestra época entorno a la información son cuatro: en primer lugar, entre libertad y coacción; en segundo lugar, entre verdad y engaño; en tercer lugar, entre transparencia y seguridad; y, finalmente y en otro plano, aunque derivado del primer par, entre aportación y recompensa (1).

Buscar el equilibro entre estos ejes en cada situación concreta -y quizá en cada clase de situaciones- constituye el dilema ético al que cada profesional e investigador de la información ha de enfrentarse.

En nuestro tiempo, libertad y cohesión aparecen, de alguna manera, como los dos polos de atracción de un espectro de valores a veces sorprendentemente líquido y fluido. Ambos valores suelen adquirir en las discusiones -e incluso dentro de las diferentes perspectivas políticas y filosóficas- categoría de absolutos, polarizando así las discusiones hasta posiciones irreconciliables; y, sin embargo, ambos son invocados en uno $u$ otro momento por los partidos en liza.

$Y$ es que, ciertamente, ambos valores tienen un carácter central en cualquier abordaje ético de la vida social y, por ende, de la actividad informacional. Nuestra opción es clara: deben ser conciliados, pero siempre minimizando el factor de coacción que inevitablemente permea la totalidad de la vida social.

Creemos, además, que existe una relación estrecha - sistémica- entre los ejes propuestos. El engaño —entendido aquí de forma amplia como no-información, no solo como mentirasurge como instrumento de coacción o como defensa contra ella, esto es, como mecanismo de ataque o seguridad. Por otra parte, la trasparencia favorece la verdad, y ésta, a su vez, potencia la autonomía de los sujetos (y, por ende, su libertad). Cuando las personas libres y autónomas reconocen al otro como un igual más allá de los intereses estrechos del momento, es posible la solidaridad; y que se trascienda el mecanismo básico del intercambio social -la reciprocidad-, que en el fondo lo que hace es garantizar el equilibrio entre la autonomía de los sujetos y su aportación al bien común.

\section{Libertad y libre cooperación}

Una cuestión recurrente en los debates éticos sobre la información en la era digital es el de la libertad. Es frecuente que en estos debates la libertad aparezca en contraposición a la propiedad, y viceversa; y, sin embargo, son problemas profundamente relacionados. En nuestra perspectiva, deben interpretarse desde el problema que las subyace a ambas, y que no es otro que el de la autonomía individual, que, por otro lado, como se defiende más adelante, es el único camino hacia el auténtico compromiso y donación de lo mejor que se puede aportar.

A pesar de los esfuerzos de ligar la libertad a constructos colectivos, se trata de un valor profundamente personal, que puede abocar al individuo al enfrentamiento con su entorno y con los intereses de los colectivos a los que pertenece y que, en principio, debería compartir.

Al final, la libertad requiere autonomía respecto a los deseos y necesidades de otras personas, y esa autonomía necesita a su vez de un espacio y unos recursos propios, es decir, de alguna forma de propiedad, sea en forma de bienes o de derechos. Estas "propiedades" alargan la seguridad en el tiempo, lo que a su vez realimenta la autonomía del sujeto.

La información es uno de esos recursos básicos; es necesaria para consolidar y realizar el 
poder personal -a través de los derechos a informarse y a informar-; y, a su vez, es intercambiable por otro tipo de recursos - por ejemplo, el dinero- por medio de instrumentos jurídicos como la propiedad intelectual. La información se guarda mediante el silencio, y se comparte dentro de redes de intercambio, esperando por lo general una recompensa, que se recibe sobre la base de la reciprocidad. La información se puede, además, utilizar como un recurso de coacción y ataque, a través de los conocidos procedimientos del engaño y la información sesgada o parcial.

La libertad, por otro lado, es la raíz del compromiso personal, sin el cual las personas no dan lo mejor de sí mismas. De hecho, cuando las personas no se ven respetadas y no reciben un trato recíproco a sus esfuerzos, reducen su nivel de compromiso progresivamente, en una escalera que pasa por el cumplimiento reluctante y que puede descender hasta el sabotaje. En situaciones de coacción sucede lo mismo. Los límites son, con todo, bastante flexibles y están determinados culturalmente.

De forma recíproca, es necesario contemplar que la persona sin espacio ni recursos propios tiene una libertad disminuida, porque no hay libertad sin autonomía, aunque los espacios de libertad existen incluso en las situaciones más estrechas y no dependen solo de factores externos (Frankl, 1985). Idealmente, a través de la solidaridad, el individuo en desventaja debería recibir la masa crítica de bienes y derechos que pudieran garantizar su autonomía, su crecimiento y su plena contribución a la sociedad. En la práctica, esto no es tan fácil, porque la dación -en una gran mayoría de las ocasiones- se produce en redes de intercambio, y está afectada por las leyes de la reciprocidad (2).

Por fin, las personas en una situación de autonomía intermedia, si existen espacios sociales de libertad, puede al menos confiar en ampliar su propio espacio y dedicarse a su propia promoción.

\section{Cohesión social y poder}

En el polo opuesto de la libertad se sitúa como valor la cohesión social. El ser humano se reproduce, defiende y subsiste dentro de grupos sociales, y esos grupos sociales son tanto más efectivos en asegurar esas funciones cuanto más cohesivos son. Lógicamente, la cohesión restringe la libertad de los individuos, aunque, ciertamente, la puede potenciar en otras áreas, en la medida en que crea oportunidades nuevas y sinergias. Si el individuo percibe ese balance como positivo, no hay problema; en caso contra- rio, empieza a percibir la situación como un yugo y los procesos de contribución se resienten.

Sin duda, desde el punto de vista contemporáneo, la cohesión social-si existe libertadminimiza los conflictos; y, en la medida en que existen proyectos comunes y una gestión adecuada, promueve el bien común. Esta es la cara de la cohesión social, la que le convierte en un objetivo digno de ser perseguido. Pero la cohesión como valor también posee su cruz, sus sombras, que cabe analizar en varios frentes.

En primer lugar, la cohesión social es resultado de la dependencia objetiva entre diversas personas que se necesitan, y genera fuerzas que transcienden al individuo.

En segundo lugar, la cohesión social se realiza necesariamente de forma jerárquica, $\mathrm{y}$, por ello, incorpora un gradiente de poder entre las personas y los grupos sociales. La cohesión social se realiza a través del poder, y el poder de unos sobre otros disminuye ciertamente la libertad de los que resultan en cada momento $-\mathrm{y}$, sin duda, sistémicamente- sujetos.

En un entorno natural este proceso se produce en un marco de reciprocidad. Hay un equilibrio entre beneficios y sacrificios que está codificado en la evolución de cada especie. Como ocurre con el resto de los animales, en los grupos humanos primitivos, el poder se relaciona de forma muy estrecha con los costes para el individuo de su aportación al grupo. Un mayor estatus significa en una alta probabilidad una mayor exposición al peligro.

Por el contrario, en las sociedades históricas el poder social incorpora el uso sofisticado de la coacción y el engaño para conseguir recursos de otras personas, minimizando el coste para el explotador.

Como resultado, a pesar de la amplia aceptación del concepto, la cohesión social tiene una historia complicada para la sensibilidad del ser humano actual, pues no nace solo de la libertad, sino también de la coacción.

\section{Coacción y explotación}

La coacción directa -la evidencia de un castigo o una privación- o indirecta -disminuyendo la capacidad de maniobra y la autonomía de los sujetos- es parte del DNA de nuestras sociedades.

Quizá a la vez que aprendieron a domesticar a plantas y animales, los seres humanos descubrieron que una manera de potenciar su influencia y poder en su entorno era multiplicándose a través del trabajo de otros seres humanos, y, 
además de en el marco de relaciones de reciprocidad, aprendieron a obtener esa colaboración mediante la coacción y el engaño (3).

Por otra parte, capitanear la cohesión -tribal, nacional, social, religiosa, vecinal, etc.- es una actividad que proporciona relevancia social, poder y recursos. Conforme las sociedades se iban complejizando y estos niveles se superponían, aprendieron a explotar las fracturas que se producían entre los grupos para alterar las estructuras de poder. $\mathrm{Y}$, aunque no hay poder legítimo sin servicio -y entonces es inestable, lo que no gusta a la mayoría de los poderosos, el poder es fácilmente instrumentalizable hacia objetivos particulares.

Para todos es obvio que la sociedad exige una articulación para funcionar, y, sin embargo, no se atiende al hecho de que el poder se ejerce siempre por sujetos individuales, aunque lo hagan en representación de colectivos y de forma colegiada y contrapesada. Esta no es cuestión accidental —como los políticos lógicamente desean transmitir-, ni siquiera estructural -ligada a un determinado sistema social y económico-, sino inherente a la lógica profunda del ejercicio del poder. Por ello, la administración del bien común sin permanente control está continuamente afectada por los intereses particulares.

La existencia del estado supone la culminación de este proceso. El estado es la forma actual de organización del poder en nuestras sociedades y se distingue por el ejercicio "legítimo" de la coacción dentro del cuerpo social. Como tal, se ha ido extendiendo e imbricando con los otros centros de poder social a lo largo de la historia y ocupa hoy en día el lugar central de la vida social. El poder del estado es ejercido por élites capaces de articular una mayoría de voluntades o, al menos, de desmovilizarlas. Y, por lo general, esas élites ejercen el poder en su beneficio con los límites que les marca el propio equilibrio que garantiza su posición hegemónica en el cuerpo social.

El problema de estados poderosos como los contemporáneos es que sus élites utilicen el poder coactivo del Estado para desarrollar agendas partidistas en perjuicio de la libertad de las personas, su autonomía y su libre cooperación. Normalmente, las élites y los partidos particulares ven positivo que se implanten sus agendas al resto de la sociedad, pero se llevan las manos a la cabeza cuando ven que lo hacen sus contrarios en sus ámbitos de influencia o en otros lugares del mundo. Es esta actitud generalizada la que muestra sin ambages los límites del uso de la coacción para desarrollar la cohesión: siempre resulta en una pérdida de libertad y de capital social, no solo porque es violenta - su aspecto fundamental-, sino porque es necesariamente una actitud partidista. Por ello, la coacción debe limitarse al mínimo necesario, y en el marco de un consenso amplísimo, y esto es bien entendido en las sociedades más avanzadas.

Por otra parte, solo una masa suficiente de ciudadanos libres -lo que implica que son autónomos, como hemos visto-, a través de las organizaciones que libremente van formando, puede ejercer ese control desde fuera del estado, aunque ciertamente en relación con él. En el campo concreto de la información, su esfuerzo por moderar el ejercicio del poder se concreta en las leyes de acceso a la información, de transparencia, de libertad de expresión, cuyo avance suele ser lento y plagado de conflictos... Procedimientos bien conocidos como la separación de poderes, la competencia pacífica entre partidos y empresas -que les obliga a tomar también la perspectiva de sujetos, no solo la de poderosos-, etc., son fundamentales, aunque la experiencia indica que son continuamente violados por los que buscan o ejercen el poder a través de contra-mecanismos como la expansión de unos poderes sobre otros, la concertación entre partidos y de estos con otros poderes, etc.

\section{Conciliando libertad y cohesión: uno de los motores de la reflexión ética}

Ciertamente, cuando libertad y cohesión se unen, se alcanza lo mejor de los dos mundos. Sin duda, la cohesión libremente buscada y sentida es el valor fundamental de la vida social, la solidaridad; del mismo modo que la libertad es la raíz de autorrealización personal - a veces reducida tan solo a libertad interior.

Así pues, libertad y cohesión social no son necesariamente incompatibles, ciertamente. La vida social promueve la autonomía individual a través de los beneficios de la especialización del trabajo y el auxilio mutuo; y la libertad promueve el compromiso social sincero y eficaz.

Pero también sucede lo contrario: muchas veces la cohesión se realiza a través de la coacción, tanto más fácil si se realiza desde el colectivo hacia el individuo, y con un alto potencial para la violencia cuando se realiza entre colectivos; y, recíprocamente, el "mal" uso de la libertad destruye el bien común. Puesto que la relación es, entonces, inherentemente conflictiva, es necesaria la reflexión ética para iluminar estos conflictos; y después la legal, para concretar sus conclusiones en el marco del ejercicio del poder social. 
En cualquier caso, una conciliación profunda entre libertad y cohesión solo puede surgir en ausencia de coacción y engaño y garantizando sus bases: la autonomía, la transparencia y la seguridad. Sus frutos son los de la solidaridad. No en vano, estos valores conforman los pilares de la reflexión ética entorno a la información.

\section{La no-información como coacción}

Un aspecto central en la ética de la información, junto con el de la libertad y la coacción, es sin duda el problema de la verdad. Se espera que la información sea completa y que sea cierta.

Es cierto que los debates ideológicos y filosóficos han puesto en duda la misma noción de verdad, y han mostrado con claridad y crudeza sus límites. Sin embargo, y a pesar de todas las disquisiciones técnicas, la práctica y el sentido común sobre la verdad de una información se abren paso sin dificultad cuando se aplican a la mayoría de las situación concretas. Y se constata continuamente que la verdad es manipulada, transgredida y retorcida.

Desde nuestro punto de vista, las estrategias contra la información -ocultamiento (incluyendo la información parcial o sesgada), sobreinformación y engaño- son formas de coacción, puesto que buscan conseguir que una persona haga o deje de hacer algo obligada, y, en definitiva, en ausencia de libertad. No se trata solo del ejercicio directo de la fuerza, sino de la privación de la autonomía de decisión que constituye la base de la libertad.

$\mathrm{Y}$, sin embargo, en un mundo donde no son extrañas la coacción y la explotación, las estrategias contra la información se consideran legítimas cuando son ejercidas por el individuo cuyo poder está disminuido; es decir, cuando se efectúan de forma defensiva. Para las personas en situaciones difíciles no proporcionar información se considera un derecho. La no información es una estrategia de seguridad. El problema es que, en una situación de conflicto, una mayoría de las personas se siente engañada antes que engañadora, y que constituye una argucia social más situarse en el papel de víctima.

A pesar de todo, lo que es cierto sin lugar a dudas es que, cada vez que se tiene que recurrir aun defensivamente a estrategias de noinformación, se produce una pérdida de potencial de colaboración o, si se quiere, de "capital social", puesto que las personas desconocen la situación real de su entorno, y pierden autonomía respecto a él, así que pueden contribuir menos. $Y$, sin embargo, solo una reducción del nivel de coacción y explotación de unas perso- nas por otras puede ayudar a resolver este tipo de problemas.

\section{Un debate difícil, pero necesario}

En fin, la información está en el centro del debate ético que hemos analizado, uno de los principales de nuestros tiempos. Por un lado, la información es un recurso, y, por tanto, es una precondición de la libertad, que se fundamenta, como hemos discutido, en la autonomía. Por el otro, la información es también un instrumento de poder político, social y económico; es necesaria para ejercerlo; y está afectada también por las tentaciones que éste conlleva.

De la difícil conciliación entre los diversos valores que rodean al concepto de información surgen los diferentes temas que se abordan en este monográfico: derecho a la información, transparencia, libertad de información, difusión de la información, censura, confidencialidad, seguridad de la información, protección de la intimidad, ética de la investigación, derechos de autor, reciprocidad y profesionalidad en el ejercicio público o privado de la información, prosecución del propio bienestar, seducción de públicos y audiencias...

Todo estos temas constituyen valores, esto es, objetivos deseables tanto desde una perspectiva individual como social. Los problemas surgen del difícil equilibrio entre ellos, su jerarquización y las inevitables consecuencias que conllevan las opciones que se tomen.

Por nuestra parte, hemos intentado que el conjunto de las contribuciones fuera lo más representativo posible en cuanto a puntos de vista y opiniones —realizando también una llamada pública a contribuir-, aunque es cierto que, cada vez más en estos tiempos de crisis, las personas con una misma opinión tienden a refugiarse en foros y ambientes en los que se comparten sus ideas e, incluso -por suerte más raramente-, a excluir los puntos de vista contrarios.

Todavía más, ante estas cuestiones -conflictivas, difíciles de discutir y plagadas de generalizaciones, saltos en el vacío y artificios retóricos-, es comprensible intentar evitar problemas y centrarse en otros aspectos teóricos o técnicos. Y, sin embargo, es necesario abordarlas.

La promoción de la convivencia y la búsqueda de la verdad exigen que las diferencias se afronten con valor y abiertamente; y, si el temple y los ánimos lo permiten -lo que se espera y es normal en personas con formación superior-, desde el respeto y la tolerancia. Creemos que esa actitud es, a pesar de todas las dificultades 
que conlleva, fructífera. De hecho, sorprende en estas páginas hasta qué punto coinciden en muchos valores y perspectivas éticas y legales personas de tradiciones nacionales e ideológicas netamente diferentes.

En cuanto a mis reflexiones personales, me gustaría destacar que, si algo nos enseña una mirada lo más lúcida posible a la realidad, es que la libertad debe ganarse continuamente $y$ en cada generación, y que la solidaridad sin coacción es el mejor camino para el desarrollo humano. Estos principios me parecen también válidos para iluminar la reflexión y la actividad ética y legal en el campo de la información y la documentación.

\section{Agradecimientos}

Conscientes de que los aspectos éticos y legales de la información constituyen temas difíciles y conflictivos, agradecemos al lector su apertura, tolerancia y disposición a abordarlos desde el conjunto mínimo de valores que necesariamente hemos de compartir en una revista científica, que son los de la indagación científica, que busca la verdad de forma transparente, contrastable, coherente y consistente.

Agradecemos enormemente su esfuerzo a los autores que han tenido la voluntad y el valor de compartir con nosotros sus puntos de vista desde esos valores. Para ellos supone descubrir y compartir sus posiciones actuales y someterse a su vez al juicio ético de sus lectores.

Finalmente, pero no en último lugar, quisiéramos agradecer su trabajo a los revisores, maquetadores, diseñadores gráficos e impresores, sin cuyo esfuerzo habría sido imposible que este volumen hubiera visto la luz.

Gracias a todos.

\section{Notas}

(1) Los dos primeros son pares de opuestos —en el sentido de la axiología-, mientras que el tercer par es complementario y el cuarto recíproco sin contingencia necesaria.

(2) Una cuestión importante es el papel que juega la demora en la gratificación, que es resultado de la educación $y$, en el adulto, también de la autoreflexión.

(3) De hecho, se hace de forma muy parecida a la que se maneja a los animales. Por ello, una estrategia de poder es disminuir la autonomía de los sujetos, privándoles de la posibilidad de reflexionar y desarrollar un pensamiento propio, un estado cultural desarrollado.

\section{Referencias}

Frankl, Viktor E. El hombre en busca de sentido. 6a. Ed. Barcelona: Herder, 1985. 
